\title{
Dinâmica da paisagem na bacia hidrográfica do Rio Apeú, nordeste do Pará, Brasil
}

\author{
Landscape dynamics in the watershed basin of the \\ Apeú River, Northeastern Pará State, Brazil
}

Shislene Rodrigues de Souza ${ }^{[a]}$, Maria de Nazaré Martins Maciel ${ }^{[b]}$, Francisco de Assis Oliveira[c] ${ }^{[c]}$ Stephan de Almeida Jesuíno[d]

[a] Engenheira florestal, Mestre do Programa de Pós-Graduação em Ciências Florestais, Universidade Federal Rural da Amazônia, Belém, PA - Brasil, e-mail: xflorest@gmail.com

[b] Engenheira florestal, Doutora, professora adjunta do Instituto Ciberespacial, Universidade Federal Rural da Amazônia, Belém, PA - Brasil, e-mail: nazare.maciel@ufra.edu.br

[c] Engenheiro florestal, Doutor, professor adjunta do Instituto de Ciências Agrárias, Universidade Federal Rural da Amazônia, Belém, PA - Brasil, e-mail: francisco.oliveira@ufra.edu.br

[d] Engenheiro florestal, Mestre do Programa de Pós-Graduação em Ciências Florestais, Universidade Federal Rural da Amazônia, Belém, PA - Brasil, e-mail: stephan.almeida@gmail.com

\section{Resumo}

Este trabalho teve como objetivo analisar espacialmente a dinâmica da paisagem da bacia hidrográfica do Rio Apeú, região nordeste do Pará, através do uso integrado de produtos e técnicas de sensoriamento remoto e geoprocessamento, num período de sete anos, visando oferecer subsídios ao planejamento de sua ocupação territorial. Para tanto foram utilizadas imagens Landsat5/TM referentes aos anos de 2001, 2004 e 2008, as quais foram classificadas pelo algoritmo de classificação supervisionada de máxima verossimilhança. Por meio da análise dos mapas temáticos gerados para os três períodos analisados, foi possível analisar a dinâmica de cobertura vegetal e uso do solo da bacia em questão. Os resultados mostraram que a paisagem da bacia é fortemente marcada pela atividade da pecuária, sendo as pastagens o padrão dominante de uso da terra. A classe de sucessão secundária, apesar de sofrer progressiva redução ao longo dos sete anos analisados, ainda é a cobertura vegetal dominante na paisagem, atribuída a sustentabilidade do sistema de produção agrícola local como componente de pousio. No dinamismo da paisagem, a floresta ombrófila densa é a classe de maior estabilidade na cobertura vegetal.

Palavras-chave: Dinâmica da paisagem. Bacia hidrográfica do Rio Apeú. Cobertura vegetal. Uso do solo.

\section{Abstract}

This paper aimed to analyze the dynamics of the vegetation cover and of the use of soil in the drainage basin of the River Apeú over a period of seven years. Landsat5/TM images obtained in 2001, 2004 and 2008 classified by the maximum verisimilitude supervised classification algorithm were used. Analysis of the thematic maps 
generated for the three distinct periods allowed for the study of the dynamics of the vegetation cover and of the use of soil. Results showed that the landscape of the basin is strongly marked by livestock production and pasture is the predominant use of the soil. The "secondary system" class, although underwent progressive reduction along the seven year period, is still the predominant cover in the landscape, which is attributed to the sustainability of the local agricultural production system, as a component of fallow. In the landscape's dynamism, the tropical rain forest is the natural coverage class which has greatest stability.

Keywords: Landscape dynamics. Watershed basin. Apeú river. Vegetation cover. Use of the soil.

\section{Introdução}

A Amazônia, área constituída de extensas coberturas vegetais, tem registrado em sua história problemas característicos de ocupação tais como desequilíbrios dos recursos naturais e problemas sociais. Para Kampel, Câmara e Monteiro (2001), o contexto político e econômico ao longo do tempo foi determinante no processo de ocupação humana e urbanização da Amazônia, reconhecidas por Pereira (1997) como fenômenos que desencadearam prejuízos econômicos, sociais e ambientais para a região.

0 nordeste do Estado do Pará é exemplo desse processo de ocupação, pois constitui uma das mais antigas áreas de colonização da Amazônia - processo que se desenvolveu com maior intensidade com a consolidação da estrada de ferro Belém-Bragança, a partir do fim do século XIX (ÉGLER, 1961; WATRIN; GERHARD; MACIEL, 2009). De acordo com Watrin, Venturieri e Sampaio (1998), hoje a paisagem da região encontra-se com níveis altos de interferência humana, resultando em áreas de vegetação secundária produzida pela agricultura tradicional.

A condição de instabilidade da paisagem dessa região vem resultando em processos negativos na sustentabilidade dos recursos naturais que, dentro de uma visão sistêmica de interdependência entre os elementos, desencadeiam, na relação dos seus componentes ambientais, níveis de degradações diferentes. Associado a essa concepção de interdependência, tem-se a paisagem sendo vista como uma parte do espaço que condiciona unidades formadas em geral por ecossistemas, estágios sucessionais de vegetação ou ainda por áreas de uso e ocupação das terras, onde, partindo de uma contínua interação, ocorre a evolução perpétua de integração dos seus elementos. Cemim et al. (2007) evidencia a quantificação da estrutura da paisagem como parâmetro validador de estudos ambientais no funcionamento de ecossistemas. Isso pode ser aplicado às bacias hidrográficas, entendidas como unidade natural da paisagem, frequentemente associadas à definição de ecossistemas, onde as áreas são extremamente sensíveis a pequenas mudanças, sejam elas oriundas de processos naturais ou ações antrópicas.

Dentro desse contexto, a bacia hidrográfica é vista como um instrumento aferidor das implicações produzidas no uso dos recursos naturais dentro e fora dos seus limites de estabelecimento natural, já que os rios são coletores naturais das paisagens, refletindo o uso e ocupação do solo de sua respectiva bacia de drenagem (GOULART; CALLISTO, 2003). Advindo da possibilidade de conciliar uma série de informações sobre os ecossistemas que vêm sofrendo rápidas mudanças, o emprego da geotecnologia contribui decisivamente para o planejamento regional e o combate a distúrbios ecológicos da paisagem que podem se dar ao longo do tempo.

Partindo dessa premissa, a pesquisa desenvolvida teve o objetivo principal de analisar espacialmente a dinâmica da paisagem da bacia hidrográfica do Rio Apeú, por meio do uso integrado de produtos e técnicas de sensoriamento remoto e geoprocessamento, num período de sete anos, visando a oferecer subsídios ao planejamento de sua ocupação territorial.

\section{Materiais e métodos}

\section{Área de estudo}

A bacia hidrográfica do Rio Apeú ocupa uma área de aproximadamente $315 \mathrm{~km}^{2}$ (JESUS, 2009; SANTOS, 2006) e está localizada no nordeste do Pará, ou, mais precisamente, na mesorregião metropolitana de Belém. A bacia se estende entre as coordenadas 
$1^{\circ} 13^{\prime} 10^{\prime \prime}$ e $1^{\circ} 27^{\prime} 37^{\prime \prime}$ de latitude Sul e $48^{\circ} 04^{\prime} 42^{\prime \prime}$ e $47^{\circ} 53^{\prime} 30^{\prime \prime}$ de longitude Oeste, sendo que aproximadamente $77 \%$ de sua área pertence ao município de Castanhal, $16 \%$ a Santa Izabel do Pará e $7 \%$, à cidade de Inhangapi. O Rio Apeú nasce na fazenda Buriti, em Castanhal, e desemboca no Rio Inhangapí (SANTOS, 2006). 0 Rio Apeú tem como afluentes os igarapés Macapazinho, Castanhal e Americano (FERREIRA, 2003), além de Janjão, Fonte Boa, Marapanim, Taiteua, Papuquara, Capiranga, Itaqui e São João (ARAÚJO, 1997).

Geologicamente, essa área é constituída dos terrenos terciários da Formação Barreiras, além dos sedimentos recentes do quaternário, representados por cascalhos, areias e argilas inconsolidadas, que ocorrem nas faixas estreitas e descontínuas, acompanhando os cursos d'água (BRASIL, 1974). As feições geomorfológicas caracterizam-se pela presença de colinas de topos aplainados e moderadamente dissecados, compondo um dos setores do planalto rebaixado amazônico e a planície sedimentar do Pleistoceno e Holoceno (BRASIL, 1974).

A cobertura vegetal está sob domínio da floresta ombrófila densa (VELOSO; GÓES FILHO, 1982) ou floresta densa de terra-firme. Em menor proporção são também encontradas formações vegetativas secundárias, reconhecidas popularmente como capoeira, que foram originadas a partir da intervenção humana ao longo da ocupação na região.

\section{Sistematização de dados georreferenciados}

A condução do tratamento e análise do banco de dados associados com as informações georreferenciadas das áreas de estudo foram realizadas nos programas Envi 4.5 (ENVI, 2009) e ArcGis 9.3 (ESRI, 2009). Visando ao levantamento multitemporal da cobertura vegetal e uso da terra, foram selecionadas imagens digitais TM/ Landsat, órbita/ ponto 223/ 061, bandas TM 3, 4 e 5, referentes aos anos de 2001, 2004 e 2008.

Como base cartográfica foram utilizadas imagens Landsat compactadas já georreferenciadas por processo de alta precisão (MrSID) e base planialtimétrica compilada a partir de dados digitais disponibilizados pelo IBGE, na escala de 1:100.000, contendo, entre outros elementos, a rede de drenagem e a malha viária existente para as áreas de estudo.

\section{Delimitação da bacia hidrográfica de estudo}

O limite da bacia do Rio Apeú se baseou em dados georreferenciados do relevo da área em questão, derivados de produtos Shuttle Radar Topography Mission - SRTM (EROS/USGS, 2008), a partir da ferramenta Hidrology, que funciona acoplada ao programa ArcGis 9.3. 0 limite da bacia, portanto, foi definido pelos divisores topográficos que circunscrevem a área de drenagem até o ponto específico.

\section{Pré-processamento de imagem}

Foi realizada a operação de georreferenciamento na imagem de 2001, menos recente, a partir da base georreferenciada por processo de alta precisão (MrSID). A seguir, foi efetuada a etapa de registro, na qual as imagens dos anos de 2004 e 2008 foram registradas considerando-se como referência a imagem já georreferenciada de 2001. De forma a buscar a uniformização dos padrões de uso da terra, presentes nas imagens selecionadas, foi realizado, por meio do programa Envi, um processo de normalização radiométrica, envolvendo as etapas de transformação dos números digitais das imagens brutas em valores de radiância, e a sua posterior conversão para refletância aparente.

\section{Processamento de imagem}

De posse do conjunto de imagens já retificadas, elas foram submetidas ao processo de classificação pelo algoritmo de máxima-verossimilhança (Maxver) que, por ser ligado ao método supervisionado, necessita de um conhecimento prévio das feições ocorrentes na área de estudo. Tal análise teve apoio do trabalho de campo, permitindo, assim, correlacionar as feições espectrais presentes nas imagens com padrões de cobertura vegetal e uso da terra observados no campo.

Após a coleta de amostras das classes de interesse, foi efetuada uma análise do desempenho delas sob limiar de 99,9\%, sendo, a seguir, gerada a classificação também com o mesmo limiar.

Uma vez identificados os alvos classificados erroneamente, os mesmos foram reclassificados associando-os à classe correta. 
Visando a reduzir a quantidade de pontos isolados observados nas imagens classificadas e, consequentemente, promover maior uniformidade nas classes definidas, aplicou-se um filtro de mediana, através de uma máscara de convolução de dimensão $3 \times 3$.

\section{Análise espaço-temporal}

A quantificação de áreas das classes de vegetação e uso do solo, para cada um dos anos envolvidos no estudo, foi realizada considerando a função 'Estatística de Classes'. Por outro lado, a etapa referente à análise da dinâmica do uso do solo nos períodos considerados foi conduzida por meio da tabulação cruzada entre imagens temáticas das datas consecutivas, ou seja, de 2001 para 2004 e de 2004 para 2008, a qual foi efetuada pelo módulo detecção de mudança do programa Envi.

A partir da inspeção de matrizes de mudanças, foi verificado o correspondente porcentual em área de uma classe que foi convertida em outra, durante os períodos de tempo analisados, bem como o percentual de área que permaneceu inalterado (i.e., a estabilidade da paisagem) entre os anos considerados, possibilitando, assim, análise das transformações dos alvos de interesse.

\section{Resultados e discussão}

\section{Análise espaço-temporal da cobertura} vegetal e uso do solo

A partir das informações obtidas de campo foi estabelecida uma legenda temática representativa das classes de cobertura vegetal e uso do solo, encontrados na área de abrangência da bacia do Rio Apeú. A definição conceitual de cada classe foi gerada a partir da classificação da vegetação proposta pelo IBGE (1992), associada a uma visão ecológica dos ecossistemas. Adicionalmente, foram também definidas as classes solo exposto, áreas de mineração e água. Assim, compondo essa legenda estão as classes:

a) floresta ombrófila densa: formações de florestas pioneiras da Amazônia oriental com árvores atingindo os $40 \mathrm{~m}$ de altura; b) sucessão secundária: vegetações em diferentes estágios de regeneração;

c) pastagem: áreas formadas por grandes extensões de terras, dominadas por espécies forrageiras;

d) agricultura/reflorestamento: áreas produtivas oriundas de monoculturas de espécies tanto agronômicas como florestais;

e) áreas de mineração: áreas que apresentam superfícies de terra exposta, ocasionada por atividades mineradoras;

f) solo exposto: regiões com nível de edificações consideráveis ou sob preparo de alguma atividade produtiva;

g) água: região que apresente exposição de corpos d'água.

Além dessas classes, foram identificadas as unidades nuvem e sombra, detectadas particularmente na imagem do ano de 2004. Na Tabela 1 estão apresentados os dados referentes à quantificação de áreas das classes de cobertura vegetal e uso do solo, extraídos das imagens temáticas correspondentes aos anos de interesse.

Tabela 1 - Quantificação de áreas definidas pelas classes de cobertura vegetal e uso do solo na Área da Bacia do Rio Apeú, nos anos de 2001, 2004 e 2008

\begin{tabular}{|c|c|c|c|c|c|c|}
\hline \multirow[b]{2}{*}{ Classes } & \multicolumn{2}{|c|}{ Área em 2001} & \multicolumn{2}{|c|}{ Área em 2004} & \multicolumn{2}{|c|}{ Área em 2008} \\
\hline & $\mathrm{km}^{2}$ & $\%$ & $\mathrm{~km}^{2}$ & $\%$ & $\mathrm{~km}^{2}$ & $\%$ \\
\hline FOD & 33,48 & 10,65 & 29,61 & 9,42 & 33,71 & 10,72 \\
\hline SSD & 145,03 & 46,14 & 131,05 & 41,69 & 91,60 & 29,14 \\
\hline PST & 75,04 & 23,87 & 81,49 & 25,92 & 121,11 & 38,53 \\
\hline AGF & 1,29 & 0,41 & 1,65 & 0,52 & 3,27 & 1,04 \\
\hline SEX & 58,49 & 18,61 & 59,01 & 18,77 & 63,27 & 20,13 \\
\hline MIN & 0,43 & 0,14 & 0,41 & 0,13 & 0,42 & 0,13 \\
\hline AGU & 0,58 & 0,19 & 0,65 & 0,21 & 0,96 & 0,31 \\
\hline NUV & - & - & 4,76 & 1,51 & - & - \\
\hline SOM & - & - & 5,73 & 1,82 & - & - \\
\hline Total & 314,35 & 100,00 & 314,35 & 100,00 & 314,35 & 100,00 \\
\hline
\end{tabular}

Legenda: FOD = floresta ombrófila densa, SSD = sucessão secundária, PST = pastagem, $A G F=$ agricultura/reflorestamento, $S E X=$ solo exposto, $\mathrm{MIN}$ = áreas de mineração, $\mathrm{AGU}=$ água, $\mathrm{NUV}=$ nuvem, $\mathrm{SOM}=$ sombra. Fonte: Dados da pesquisa. 
Dentro de uma visão horizontal, a bacia do Rio Apeú com uma área de aproximadamente 314,35 $\mathrm{km}^{2}$ apresenta como característica predominante na paisagem as classes: floresta de sucessão secundária, pastagem e solo exposto. A caracterização de uma formação socioeconômica construída essencialmente da base agropecuária, bem como em função dos grandes comércios nos centros urbanos, já foi relatada por Denich (1991), que atribui como fator preponderante a colonização dessas terras.

A classe sucessão secundária, apesar de evidenciar-se uma progressiva redução ao longo dos sete anos analisados, ainda é a cobertura vegetal dominante na área. A ocupação expressiva dessa classe tem muito a ver com a sustentabilidade do sistema de agricultura tradicional praticado na região, que depende principalmente de períodos de pousios suficientemente longos para restabelecer os estoques de nutrientes e matéria orgânica utilizados e/ou perdidos no período agrícola (KATO et al., 2004). Porém, esse período de pousio vem diminuindo em virtude do aumento populacional e da redução da disponibilidade de vegetações secundárias na região (WATRIN; GERHARD; MACIEL, 2009), aumentando assim a pressão sobre essa classe, que tem a perda da fertilidade como uma das principais características na conversão das áreas de sucessão secundárias para as práticas da agricultura itinerante (SCHMITZ, 2007).

No que diz respeito às áreas ocupadas pela classe de floresta ombrófila densa, observou-se uma pequena oscilação durante o período analisado. Em 2001 encontraram-se valores de 10,65\%; já em 2004 esse valor passou para $9,42 \%$, e em 2008 , o valor encontrado foi de $10,72 \%$. 0 decréscimo de valor ocorrido no ano de 2004 deve-se à ocorrência de nuvens e sombras em uma determinada área de floresta. Vale salientar que durante as análises foi possível perceber que a formação floresta ombrófila densa está em grande parte restrita ao longo dos cursos d'água.

A pastagem é a unidade de uso do solo mais expressiva na área da bacia, evidenciando uma região com atividade fortemente voltada para a pecuária (Tabela 1). Esses resultados coincidem com os observados em muitas áreas do Estado do Pará (MCCRACKEN et al., 1999; MERTENS et al., 2002; WATRIN; GERHARD; MACIEL, 2009), onde a feição de maior evidência, em termos de área, corresponde às pastagens em seus diferentes estados. Fearnside (2001) estima que pelo menos $80 \%$ das áreas desflorestadas na Amazônia es- tão ocupadas com pastagens cultivadas ou constituem vegetação secundária oriunda de áreas de pastagens degradadas e/ou abandonadas (principalmente sob tutela de grandes proprietários de terra), onde o processo de desflorestamento se dá de forma muito mais intensa sob condições de ocupação territorial.

Ainda como pode ser notado na Tabela 1, a classe pastagem apresenta um aumento de 2,05\% do ano de 2001 para 2004 , e de $12,61 \%$ de 2004 para 2008. 0 grande incremento no último período acredita-se estar intrinsecamente ligado aos altos preços de mercado alcançados pela arroba da carne bovina nos últimos anos, saindo de uma média anual de R\$ 41,67 em 2001, passando por $\mathrm{R} \$ 58,08$ em 2004, e chegando a R\$ 81,06 em 2008 (SÃO PAULO, 2010). Segundo Santos (2006), o surgimento das atividades agropecuárias na Amazônia teve início na década de 60 , com investimentos do governo federal através da Superintendência de Desenvolvimento da Amazônia (Sudam), que, de acordo com Costa (2000), chegou a aprovar $87,8 \%$ dos recursos aplicados no meio rural para a pecuária. Mais tarde, o envolvimento com a atividade somente se intensificou com o surgimento de outros programas criados pelo governo, como o Proterra e o Polamazônia, que, no mais, não tinham o pequeno trabalhador rural como alvo principal dos benefícios. Os processos associados à expansão da pecuária têm se mostrado, portanto, extremamente resistentes. Isso se dá não por uma causa única, como a rentabilidade específica da atividade, mas é o resultado da interação complexa de múltiplas causas (PIKETTY et al., 2004; RODRIGUES, 2004). Essas causas estão associadas, principalmente, à liquidez da atividade, à relativa simplicidade dos processos produtivos, bem como ao baixo nível de investimento de capital necessário à sua instalação.

Para Mertens et al. (2002), a dinâmica das pastagens em áreas de fronteira agrícola na Amazônia reflete não apenas a necessidade direta de fornecer alimentação para o rebanho, mas apresenta outras funções para os atores sociais envolvidos no processo, tais como a apropriação e valorização da terra. Segundo Veiga et al. (2001), a pastagem é o uso da terra principal nessas áreas em virtude de ser a estratégia mais comum entre todos os atores sociais, pois é o caminho mais barato e eficiente de obter o controle efetivo da área quando comparados com todos os demais sistemas de uso da terra. Assim, considerando que as pastagens permitem aumentar o 
valor da terra no mais baixo custo e por um longo prazo, Mertens et al. (2002) destacam que para ambos os propósitos, agrícola e econômico, as pastagens têm se mostrado como o melhor uso da terra no contexto da especulação de terras, mesmo nos casos das áreas em que esse processo não seja evidente.

A classe agricultura/reflorestamento apresenta um modesto crescimento ao longo dos anos analisados, passando de $1,29 \mathrm{~km}^{2}$ em 2001 para 1,65 km em 2004, chegando a atingir o valor de $3,27 \mathrm{~km}^{2} \mathrm{em}$ 2008. Graças ao predomínio de pequenos produtores na região cultivando áreas muito reduzidas (roças), houve restrições no processo de detecção remota dessas áreas. Isso, aliado ao fato das culturas anuais estarem, muitas vezes, na fase de pós-colheita durante a tomada das imagens, fez com que as áreas agrícolas se mostrassem pouco expressivas.

Tendo como base predominante ainda o sistema de subsistência, a agricultura praticada em Castanhal, Santa Isabel e Inhangapí englobam, segundo a SepofPA $(2007 \mathrm{a}, \mathrm{b}, \mathrm{c})$, entre seus principais produtos: o feijão (Phaseolos vulgaris L.), a mandioca (Manihot esculanta L.), o milho (Zea mays L.), o dendê (Elaeis guineensis) e a pimenta-do-reino (Piper nigrum L.). Geralmente plantados consorciados, esses produtos já obtiveram várias mudanças na economia dessas cidades, em particular no município de Castanhal. Muitas dessas transformações ocorreram por meio dos recursos promovidos pelo FNO (ALMEIDA, 2004).

Ainda falando sobre as mudanças que a base agrícola vem promovendo, dentro da conjuntura política de crescimento da produção está a implementação de novas culturas e serviços rurais oferecidos ao pequeno produtor, tais como as culturas florestais. Santos (2006) já mencionava o reflorestamento sendo implantado em algumas propriedades na área da bacia. Assim, seja para fins comerciais ou para fins ambientais, o reflorestamento mostra-se como uma alternativa na geração de renda e de recuperação de áreas degradadas, dado principalmente pelas condições ambientais encontradas na região. Entre as espécies mais utilizadas estão o paricá (Schizolobium amazonicum Huber ex Ducke), o mogno africano (Khaya ivorensis A. Chev.) e a teca (Tectona grandis L.f).

A classe solo exposto, como terceira classe de maior dominância em todos os anos na área da bacia do Rio Apeú, pressupõe a expressividade dada ao acelerado crescimento urbano dos municípios que envolvem a bacia. Estimativas da Sepof-PA, baseadas em dados do IBGE (2007a, b, c), revelam que em 2000, enquanto as populações urbanas de Castanhal, Santa Izabel e Inhangapí eram respectivamente de $121.249,33.078$ e 2.036 habitantes, em 2007 já chegavam a 146.116, 39.522 e 2.265 habitantes respectivamente, mostrando que os municípios de Castanhal e Santa Izabel tiveram um incremento populacional na ordem de $20 \%$, enquanto que Inhangapi, na ordem de 11\%. Dentre esses, Castanhal e Santa Izabel são os mais intimamente ligados aos processos de transformação da paisagem da bacia do Rio Apeú, pois 93\% da área dela está englobada nesses municípios. Adicionalmente, o aumento de $4,78 \mathrm{~km}^{2}$ de solo exposto pode ser explicado eventualmente pela presença das culturas anuais no momento da tomada das imagens, onde, considerando uma condição de colheita ou pós-colheita, haverá uma pequena resposta espectral de cobertura vegetal do solo, caracterizando-o, assim, como solo exposto.

As áreas de mineração, caracterizadas pela extração de areia, embora presentes na paisagem da bacia se mostram praticamente inalteradas em termos de área no período analisado, constituindo uma classe pouco expressiva, ocupando uma área em torno de $0,4 \mathrm{~km}^{2}$ da área da bacia.

Agora, dentro de uma visão vertical, são apresentadas nas Tabelas 2 e 3 as matrizes de mudança entre as classes de cobertura vegetal e uso do solo que compõem a área da bacia para o período avaliado. Nesse sentido, os dois intervalos de tempo foram relativamente dinâmicos: no período de 2001 para 2004, $57,08 \%$ da cobertura vegetal e uso do solo na bacia do Rio Apeú permaneceu inalterada; já em 2004 para 2008 , esse percentual diminuiu para $55,77 \%$.

Foi observado que, dentre as classes de cobertura vegetal consideradas, a floresta ombrófila densa apresentou os maiores percentuais de estabilidade, ficando acima de $65 \%$ para os dois períodos analisados, denotando que, a despeito da crescente intervenção antrópica que vêm sofrendo, os remanescentes florestais vêm sendo ainda relativamente preservados. Essas áreas, quando não permaneceram estáveis, apresentaram um comportamento diferenciado de acordo com o período enfocado, sendo convertidas ora para os estágios da sucessão secundária, ora para unidades de pastagem e solo exposto.

Observa-se que a classe de sucessão secundária apresentou uma dinâmica semelhante para os dois períodos analisados. Os percentuais de estabilidade 
Tabela 2 - Matriz de mudanças percentuais das classes de cobertura vegetal e uso do solo entre os anos de 2001 e 2004, para a área da bacia hidrográfica do Rio Apeú

\begin{tabular}{lrrrrrrr}
\hline & \multicolumn{7}{c}{2001} \\
\cline { 2 - 8 } 2004 & FOD & SSD & PST & AGF & SEX & MIN & AGU \\
\hline FOD & $\mathbf{6 5 , 6 1}$ & 7,65 & 1,24 & 0,13 & 0,93 & 0,00 & 1,21 \\
SSD & 19,56 & $\mathbf{5 5 , 6 1}$ & 23,04 & 2,21 & 11,89 & 1,94 & 1,41 \\
PST & 6,12 & 25,76 & 49,11 & 3,29 & 33,31 & 3,40 & 1,59 \\
AGF & 0,01 & 0,15 & 0,08 & $\mathbf{8 2 , 8 6}$ & 0,50 & 0,00 & 1,00 \\
SEX & 6,23 & 7,39 & 22,56 & 5,63 & $\mathbf{4 9 , 5 9}$ & 18,62 & 28,39 \\
MIN & 0,05 & 0,04 & 0,02 & 0,00 & 0,13 & 50,09 & 14,74 \\
AGU & 0,14 & 0,05 & 0,13 & 0,00 & 0,36 & 25,95 & $\mathbf{5 1 , 2 4}$ \\
NUV & 0,93 & 1,39 & 2,03 & 4,68 & 1,46 & 0,00 & 0,00 \\
SOM & 1,35 & 1,96 & 1,79 & 1,20 & 1,83 & 0,00 & 0,42 \\
\hline
\end{tabular}

Legenda: FOD = floresta ombrófila densa, SSD = sucessão secundária, $P S T$ = pastagem, AGF = agricultura/reflorestamento, SEX = solo exposto, MIN = áreas de mineração, $A G U$ = água, NUV = nuvem, SOM = sombra.

Fonte: Dados da pesquisa.

se mostraram expressivos, com valores acima de $50 \%$. A evolução dessas áreas para a classe floresta ombrófila densa esteve na ordem de 7,65\% e 8,76\% respectivamente para os dois períodos. Por outro lado, as áreas de sucessão secundária que não evoluíram para o estágio de floresta dentro do processo sucessional normal, foram incorporadas ao processo produtivo para formação, principalmente, de áreas de pastagem, com taxas de conversão de $25,76 \%$ e $26,96 \%$ para os dois períodos consecutivos.

Em relação às classes de uso do solo, as áreas de agricultura foram as que permaneceram mais inalteradas, com valores de estabilidade de $82,86 \%$ no primeiro período e de $97,24 \%$ no segundo período. Vale lembrar que os principais elementos que compõem essa classe são os plantios de espécies perenes, o que explica o seu alto valor de estabilidade, uma vez que os plantios de culturas anuais, caracterizados regionalmente como roças, mostram-se pouco expressivos em função de suas reduzidas áreas de cultivo e pelo fato de as culturas anuais estarem, muitas vezes, em fase de pós-colheita durante a tomada das imagens.

Quanto à classe pastagem, pode-se perceber que essa unidade de uso é expressiva na área da bacia do Rio Apeú, com estabilidade de 49,11\% de 2001
Tabela 3 - Matriz de mudanças percentuais das classes de cobertura vegetal e uso do solo entre os anos de 2004 e 2008, para a Área da bacia hidrográfica do Rio Apeú

\begin{tabular}{lrrrrrrrrrr}
\hline & \multicolumn{10}{c}{2004} \\
\cline { 2 - 10 } 2008 & FOD & SSD & PST & AGF & SEX & MIN & AGU & NUV SOM \\
\hline FOD & 66,39 & 8,76 & 0,84 & 0,00 & 1,56 & 0,00 & 1,21 & 0,92 & 1,35 \\
SSD & 24,23 & 53,94 & 8,14 & 0,10 & 7,36 & 1,39 & 0,00 & 1,39 & 1,96 \\
PST & 5,78 & 26,96 & 66,97 & 1,38 & 42,25 & 1,37 & 1,99 & 2,02 & 1,80 \\
AGF & 0,16 & 0,49 & 0,64 & 97,24 & 0,55 & 0,00 & 0,00 & 4,93 & 1,41 \\
SEX & 3,28 & 9,67 & 23,22 & 1,28 & 47,86 & 19,37 & 28,98 & 1,45 & 1,84 \\
MIN & 0,00 & 0,05 & 0,05 & 0,00 & 0,08 & 50,99 & 13,96 & 0,00 & 0,00 \\
AGU & 0,16 & 0,12 & 0,15 & 0,00 & 0,34 & 26,88 & 53,86 & 0,00 & 0,00 \\
\hline
\end{tabular}

Legenda: $F O D$ = floresta ombrófila densa, SSD = sucessão secundária, $P S T$ = pastagem, AGF = agricultura/reflorestamento, SEX = solo exposto, MIN = áreas de mineração, $A G U$ = água, NUV = nuvem, SOM = sombra.

Fonte: Dados da pesquisa.

a 2004 , e de $66,97 \%$ de 2004 a 2008 . No primeiro período observou-se que $23,04 \%$ das áreas de pastagem foram convertidas para sucessão secundária, enquanto que no segundo período essa taxa caiu para 8,14\%. Esse tipo de conversão é caracterizado pela prática de abandono das pastagens pela perda de produtividade, sendo relacionada a problemas tais como manejo inadequado e falta de capital para realizar reforma dessas áreas. Foram evidenciadas também taxas de conversões de pastagem em solo exposto acima de $20 \%$ em ambos os períodos, o que é explicado pela prática de limpeza e renovação das pastagens desenvolvida na área de estudo.

A classe de solo exposto obteve uma taxa de estabilidade de 49,59\% e 47,86\% respectivamente para os dois períodos analisados, o que é explicado pelo fato de que nessa classe estão relacionadas também as áreas urbanas, que normalmente apresentam grandes áreas de estabilidade. A dinâmica observada evidencia também a expansão da pecuária, em que se registram altos níveis de conversão de solo exposto para a classe de pastagem, com 33,31\% no intervalo de 2001 a 2004, e 42,25\% no intervalo de 2004 a 2008.

Nas áreas de mineração, representadas pela exploração areia, observa-se taxas de estabilidades em torno de $50 \%$ em ambos os períodos. Percebe-se uma tendência de se converter essas áreas para as 
classes de solo exposto e água. Tal conversão é típica do próprio dinamismo da atividade, onde após a retirada dos minerais, o solo fica completamente exposto, formando lâminas d'água em sua superfície ou mesmo grandes poças de água.

A classe água caracterizou-se por taxas de estabilidades acima de $50 \%$ para ambos os intervalos de tempo analisados. No geral, esta classe foi predominantemente convertida para solo exposto com taxas de conversão em torno de $28 \%$ nos dois períodos estudados. Tal comportamento pode estar ligado a diversos fatores que vão desde a periodicidade dos cursos d'água (rios perenes ou intermitentes) até as condições de umidade de elementos da paisagem, tais como a vegetação e o solo (Tabela 2).

As Figuras 1 e 2 mostram a síntese do dinamismo ocorrido na paisagem da bacia hidrográfica do Rio Apeú no período de 2001 a 2004, e 2004 a 2008, respectivamente, em termos de perdas e ganhos de cobertura vegetal, evidenciados pelo processo de desmatamento (perdas) e de sucessão florestal (ganhos).

Desse modo, verifica-se que o total de perdas de cobertura vegetal observado entre os anos de 2001 e 2004 foi de $52,50 \mathrm{~km}^{2}$, o que representa uma taxa de desmatamento de $29,4 \%$. Por outro lado, verifica-se um ganho em cobertura vegetal pelo processo de sucessão florestal de $24,28 \mathrm{~km}^{2}$ (Figura 1). Assim, considerando as perdas e ganhos de cober-

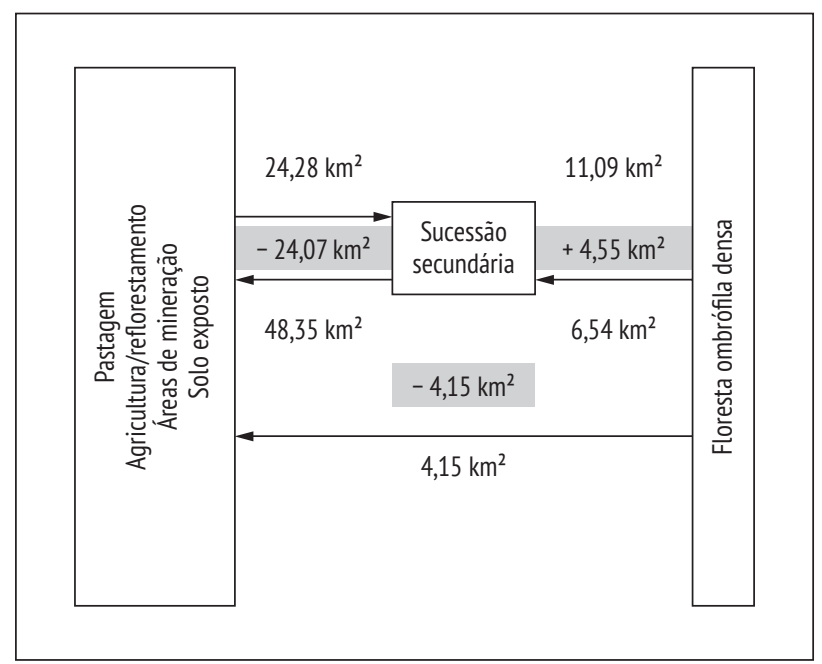

Figura 1 - Dinamismo ocorrido na paisagem da bacia hidrográfica do Rio Apeú no período de 2001 a 2004, em termos de perdas e ganhos de cobertura vegetal

Fonte: Dados da pesquisa. tura vegetal, é possível evidenciar uma perda líquida de $28,22 \mathrm{~km}^{2}$, o que representa $9 \%$ da área da bacia hidrográfica do Rio Apeú.

Em síntese, para o segundo período analisado, verifica-se que houve um total de perda em cobertura vegetal de $51,44 \mathrm{~km}^{2}$, registrando uma taxa de desmatamento de $32 \%$. 0 ganho de cobertura vegetal pela regeneração florestal, por sua vez, foi equivalente a $10,98 \mathrm{~km}^{2}$ (Figura 2). Desse modo, fazendo-se o balanço de perdas e ganhos de cobertura vegetal chega-se à perda líquida de $40,46 \mathrm{~km}^{2}$, o que representa $13 \%$ da área da bacia.

Esse cenário reflete a grande pressão da ação antrópica sobre a cobertura vegetal da bacia, com altas taxas de desmatamento, associada principalmente à expansão de áreas de pastagens.

\section{Conclusão}

Dentro do contexto de estudo proposto pela pesquisa, entre o período de 2001 a 2008, a atividade da pecuária mostra-se em expansão, sendo que as pastagens representam o padrão dominante de uso da terra, em todos os anos analisados. Nesse sentido, a área da bacia hidrográfica do Rio Apeú apresenta comportamentos semelhantes de algumas regiões do Estado do Pará, onde a pecuária desenvolve-se com

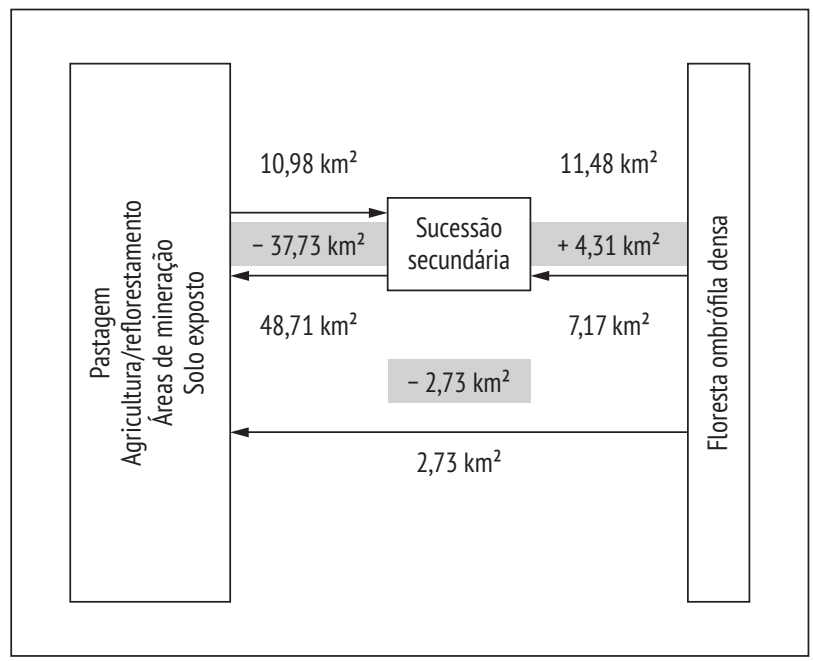

Figura 2 - Dinamismo ocorrido na paisagem da bacia hidrográfica do Rio Apeú no período de 2004 a 2008, em termos de perdas e ganhos de cobertura vegetal

Fonte: Dados da pesquisa. 
iniciativas do setor público e sem ainda grandes processos tecnológicos mais avançados.

A classe de sucessão secundária, apesar de sofrer progressiva redução ao longo dos sete anos analisados, ainda é a cobertura vegetal dominante na paisagem da bacia do Rio Apeú. A ocupação significativa dessa classe é atribuída à sustentabilidade do sistema de produção agrícola local como componente de pousio para o restabelecimento dos estoques de nutrientes e matéria orgânica utilizados e/ou perdidos no período agrícola.

No processo de mudança da paisagem, a floresta ombrófila densa é a classe de maior estabilidade na cobertura vegetal, estando concentrada principalmente às margens dos rios e igarapés que compõem a rede hidrográfica da bacia do Rio Apeú, formando Áreas de Preservação Permanente.

Existe uma grande pressão antrópica sobre a cobertura vegetal da bacia do Rio Apeú, com taxas de desmatamentos em torno de $30 \%$ registradas entre os anos de 2001 e 2008. Pode-se dizer que o problema está associado principalmente à expansão de áreas de pastagens, haja vista que foi a unidade de uso do solo que mais ocorreu na área da bacia hidrográfica do Rio Apeú. No entanto, esse desmatamento foi em parte compensado pela regeneração florestal como componente de pousio no sistema tradicional de cultivo da região.

A evolução da paisagem na área da bacia do Rio Apeú reflete de maneira geral a ocupação da Amazônia oriental no nordeste do Pará, onde a tomada do espaço territorial se faz de forma desorganizada e acelerada. Nesse âmbito, abrem-se precedentes para os impactos ambientais que vêm logo após as intervenções no uso dos recursos naturais.

\section{Referências}

ALMEIDA, J. S. Os impactos do Fundo Constitucional de Financiamento do norte na agricultura do Município de Castanhal. 2004. 108 f. Dissertação (Mestrado em Planejamento do Desenvolvimento) - Núcleo de Altos Estudos Amazônicos, Universidade Federal do Pará, Belém, 2004.

ARAÚJO, P. P. (Org.). Castanhal: estudo de pesquisa e comprovação hidrológica escala 1:8.000. Belém: CPRM, 1997. [s.p] il. Programa de Apoio à Gestão Territorial - GATE.
BRASIL. Ministério das Minas e Energia (MME). Departamento Nacional de Produção Mineral. Projeto RADAMBRASIL. Folha AS 22 e AS 23, Belém, PA; São Luis, MA: Geologia, solos, vegetação e uso potencial da terra. Rio de Janeiro, 1974.

CEMIM, G. et al. Análise estrutura da paisagem da sub-bacia do Arroio Boa Vista, RS: uma abordagem em Ecologia de Paisagem. In: SIMPÓSIO BRASILEIRO DE SENSORIAMENTO REMOTO, 13., 2007, Florianópolis. Anais... São José dos Campos: INPE, 2007. p. 3821-3828.

COSTA, F. A. Formação agropecuária da Amazônia: os desafios do desenvolvimento sustentável. Belém: NAEA/ UFPA, 2000.

DENICH, M. A importância de uma vegetação secundária nova para o incremento da produtividade do sistema de produção na Amazônia oriental brasileira. Belém: EMBRAPA/CPATU-GTZ, 1991.

EARTH RESOURCES OBSERVATION AND SCIENCE/UNITED STATES GEOLOGICAL SURVEY (EROS/USGS). Base de dados da missão SRTM. Disponível em: <ftp://e0srp01u.ecs. nasa.gov/srtm/version2/SRTM3>. Acesso em: 3 fev. 2008.

ÉGLER, E. G. A zona bragantina no Estado do Pará. Revista Brasileira de Geografia, Rio de Janeiro, v. 23, n. 3, p. 527-555, 1961.

ENVIRONMENT FOR VISUALIZING IMAGES - ENVI. Guia do ENVI. Disponível em: <http://www.envi.com.br/guia_ envi>. Acesso em: 5 nov. 2009.

ENVIRONMENTAL SYSTEMS RESEARCH INSTITUTE - ESRI. Programa ArcGis. Disponível em: <www.esri.com/software/arcgis/index.html>. Acesso em: 20 fev. 2009.

FEARNSIDE, P. M. Land-tenure issues as factors in environmental destruction in Brazilian Amazonia: the case of southern Pará. World Development, v. 29, n. 8, p. 1361 1372, 2001.

FERREIRA, J. C. V. (Org.). 0 Pará e seus municípios. Belém: SEMEAR; Rede Celpa, 2003. p. 443-445.

GOULART, M. D. C.; CALLISTO, M. Bioindicadores de qualidade de água como ferramenta em estudo de impacto ambiental. Revista da FAPAM, Minas Gerais, n. 1, p. 153164, 2003.

INSTITUTO BRASILEIRO DE GEOGRAFIA E ESTATÍSTICA IBGE. Manual técnico da vegetação brasileira. Rio de Janeiro: IBGE, 1992. 
JESUS, A. A. S. de. Geoprocessamento aplicado a estimativa de perda de solos por erosão laminar na bacia hidrográfica do Rio Apeú (Nordeste do Pará) - Amazônia Oriental. 2009. 102 f. Dissertação (Mestrado em Ciências Agronômicas) - Setor de Agronomia, Universidade Federal Rural da Amazônia, Belém, 2009.

KAMPEL, S. A.; CÂMARA, G.; MONTEIRO, A. M. V. Análise espacial do processo de urbanização da Amazônia. Relatório Técnico. Programa de Ciência e Tecnologia para Gestão de Ecossistemas, ação "métodos, modelos e geoinformação para a gestão ambiental". Instituto Nacional de Pesquisas Espaciais - INPE, dez. 2001.

KATO, O. R. et al. Plantio direto na capoeira. Ciência e Ambiente: Práticas Agroecológicas, v. 29, p. 99-111, 2004.

MCCRACKEN, S. D. et al. Remote sensing and GIS at farm property level: demography and deforestation in the Brazilian Amazon. Photogrammetric Engineering \& Remote Sensing, v. 65, n. 11, p. 1311-1320, 1999.

MERTENS, B. et al. Crossing spatial analyses and livestock economics to understand deforestation process in the Brazilian Amazonia: the case of São Félix do Xingu in south Pará. Agricultural Economics, v. 27, p. 269-294, 2002.

PARÁ. Secretaria Executiva de Estado de Planejamento, Orçamento e Finanças - SEPOF. Estatística Municipal: Castanhal. 2007a. Disponível em: <http://iah.iec.pa.gov.br/ iah/fulltext/georeferenciamento/castanhal.pdf>. Acesso em: 15 out. 2009.

PARÁ. Secretaria Executiva de Estado de Planejamento, Orçamento e Finanças - SEPOF. Estatística Municipal: Santa Izabel do Pará. 2007b. Disponível em: <http://iah.iec.pa. gov.br/iah/fulltext/georeferenciamento/staisapa.pdf>. Acesso em: 15 out. 2009.

PARÁ. Secretaria Executiva de Estado de Planejamento, Orçamento e Finanças - SEPOF. Estatística Municipal: Inhangapí. 2007c. Disponível em: <http://iah.iec.pa.gov. $\mathrm{br} /$ iah/fulltext/georeferenciamento/inhangapi.pdf>. Acesso em: 15 out. 2009.

PEREIRA, J. M. O processo de ocupação e desenvolvimento da Amazônia: a implementação de políticas públicas e seus efeitos sobre o meio ambiente. Revista de Informação Legislativa, v. 34, n. 134, p. 75-85, 1997.
PIKETTY, M. G. et al. Por que a pecuária está avançando na Amazônia Oriental? In: SAYAGO, D.; TOURRAND, J.-F.; BURSZTYN, M. (Ed.). Amazônia: cenas e cenários. Brasília: Universidade de Brasília, 2004. p. 169-192.

RODRIGUES, R. L. V. Análise dos fatores determinantes do desflorestamento na Amazônia Legal. 2004. 249 f. Tese (Doutorado em Planejamento Energético) - Universidade Federal do Rio de Janeiro, Rio de Janeiro, 2004.

SANTOS, O. C. O. Análise do uso do solo e dos recursos hídricos na microbacia do Igarapé Apeú, Nordeste do Estado do Pará. 2006. 256 f. Tese (Doutorado em Geografia) - Universidade Federal do Rio de Janeiro, Rio de Janeiro, 2006.

SÃO PAULO (Estado). Instituto de Economia Agrícola do Estado de São Paulo (IEA). Disponível em: <http://www. iea.sp.gov.br>. Acesso em: 8 abr. 2010.

SCHMITZ, H. A transição da agricultura itinerante na Amazônia para novos sistemas. Resumos do II Congresso Brasileiro de Agroecologia. Revista Brasileira de Agroecologia, v. 2, n. 1, p. 46-49, 2007.

VEIGA, J. B.; ALVES, A. M. N.; POCCARD-CHAPUIS, R. Cattle ranching, land use and deforestation in Brasil, Peru and Ecuador. Projeto IAI - NSF. Equipe Amazônia Oriental. 2001. 149 p. Relatório de Pesquisa.

VELOSO, H. P.; GÓES FILHO, L. Fitogeografia brasileira: classificação fisionômica-ecológica da vegetação neotropical. Salvador: Projeto RADAMBRASIL, 1982.

WATRIN, O. S.; GERHARD, P.; MACIEL, M. N. M. Dinâmica de uso da terra e configuração da paisagem em antigas áreas de colonização de base econômica familiar, no nordeste do Estado do Pará. Geografia, v. 34, n. 3, p. 455-472, 2009.

WATRIN, O. S.; VENTURIERI, A.; SAMPAIO, M. N. Análise multitemporal do uso da terra e suas interrelações com a cobertura vegetal em comunidades rurais do nordeste paraense. In: SIMPÓSIO BRASILEIRO DE SENSORIAMENTO REMOTO, 9., 1998, Santos. Anais..., São José dos Campos: INPE, 1998. p. 1573-1583.

Recebido: 29/06/2010 Received: 06/29/2010

Aprovado: 24/08/2011 Approved: 08/24/2011 